\title{
Predicting Effects of Cold Shock: Modeling the Decline of a Thermal Plume
}

by

C. D. Becker

D. S. Trent

M. J. Schneider

October 1977

Prepared for the

U.S. Department of Energy

under Contract EY-76-C-06-1830 


\title{
NOTICE
}

This report was prepared as an account of work sponsored by the United States Government. Neither the United States nor the Department of Energy, nor any of their employees, nor any of their contractors, subcontractors, or their employees, makes any warranty, express or implied, or assumes any legal liability or responsibility for the accuracy, completeness or usefulness of any information, apparatus, product or process disciosed, or represents that its use would not infringe privately owned rights.

The views, opinions and conclusions contained in this report are those of the contractor and do not necessarily represent those of the United States Government or the United States Department of Energy

\author{
PACIFIC NORTHWEST LABORATORY \\ operated by \\ BATTELLE \\ for the \\ UNITED STATES DEPARTMENT OF ENERGY \\ Under Contract EY-76-C-06-1830
}

\author{
Printed in the United States of America \\ Available from \\ Vational Technical Intormation Service \\ United States Department of Commerce \\ 5285 Port Royal Road \\ Springfield, Virginia 22151 \\ Price: Printed Copy 5 ; Microtithe $\$ 3.00$
}

$\begin{array}{cc} & \text { NTIS } \\ \text {-Pages } & \text { Selling Price } \\ 001-025 & 54.50 \\ 026-050 & 55.00 \\ 051-075 & 55.50 \\ 076-100 & \$ 6.09 \\ 101-125 & 56.50 \\ 126-150 & 57.01 \\ 151-175 & 57.75 \\ 176-220 & 58.50 \\ 201-225 & 59.73 \\ 226-250 & 59.00 \\ 251-225 & 510.00 \\ 276-300 & 510.25\end{array}$


PNL-2411

UC-11

\title{
Predicting Effects of Cold Shock: Modeling the Decline of a Thermal Plume
}

\author{
by \\ C. D. Becker ${ }^{1}$ \\ D. S. Trent ${ }^{2}$ \\ M. J. Schneider ${ }^{1}$
}

October 1977

1 Freshwater Sciences, Ecosystems Department

2Engineering Technology Department

Battelle

Pacific Northwest Laboratories

Richland, Washington 99352 
,

ง 


\section{PREDICTING EFFECTS OF COI.D SHOCK: MODELING \\ THE DECLINE OF A THERMAL PLUME}

C. D. Becker, D. S. Trent, and M. J. Schneider

\section{ABSTRACT}

Predicting direct impact of cold shock on aquatic organisms after termination of power plant thermal discharges requires thermal tests that provide quantitative data on the resistance of acclimated species to lower temperatures. Selected examples from the literature on cold shock resistance of freshwater and marine fishes are illustrated to show predictive use. Abrupt cold shock data may be applied to field situations involving either abrupt or gradual temperature declines, but yield conservative estimates under the latter conditions. Gradual cold shock data may be applied where heated plumes gradually dissipate because poikilotherms partially compensate for lowering temperature regimes. A simplified analytical model is presented for estimating thermal declines in terminated plumes originating from offshore, submerged discharges where shear current and boundary effects are minimal. When applied to site-specific conditions, the method provides time-temperature distributions for correlation with cold resistance data and, therefore, aids in assessing cold shock impact on aquatic biota. 


\section{CONTENTS}

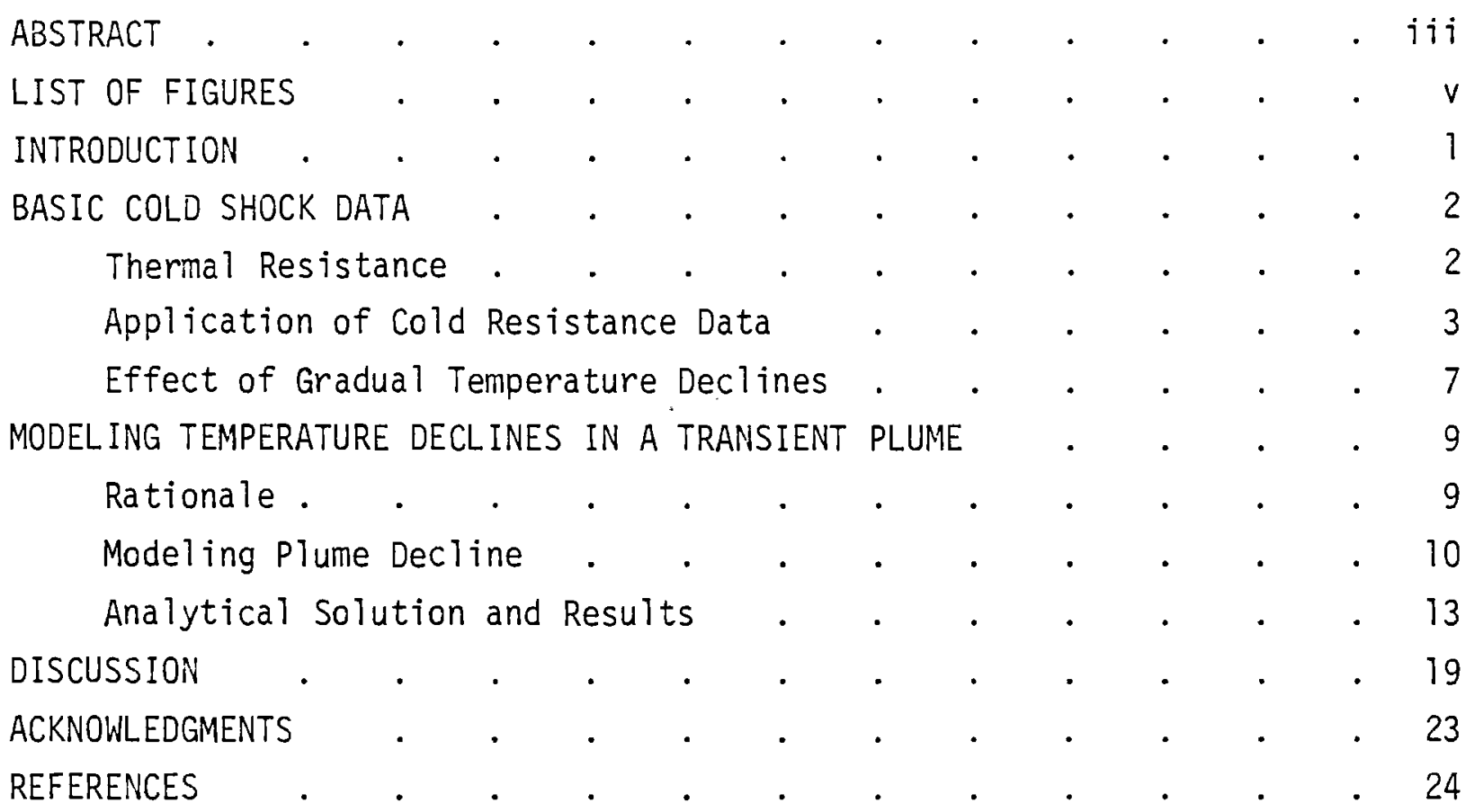




\section{LIST OF FIGURES}

1. Lower temperature tolerance diagram for a hypothetical cold-blooded aquatic organism.

2. Resistance of selected freshwater fish to cold, based on declines from incremental (acclimation) to natural (ambient) temperatures.

3. Resistance of selected marine and estuarine fish to cold, based on decline from incremental (acclimation) to natural (ambient) temperatures.

4. Temperature decline in a cooling water discharge canal at the Sundance Plant, Lake Wabamum, Alberta, Canada after shutdown on February 8, 1973.

5. Plume decay model, initial analytical conditions for Cases A, B and C. . . . . . . . . . . . . 15

6. Case A. Radial temperature distribution, Uniform Disc. . . 16

7. Case A. Decay rate of maximum (centerline) temperature, Uniform Disc.

8. Case B. Radial temperature distribution, Gaussian. . . 17

9. Case B. Decay rate of maximum (centerline) temperature, Gaussian.

10. Case C. Radial temperature distribution, Vertical Port. . . 18

11. Case C. Decay rate of maximum (centerline) temperature, Vertical Port.

12. Case A. Centerline temperature behavior at terms of at and $\varepsilon t / R_{0}^{2}$. 


\section{INTRODUCTION}

Potential sources of lethal cold shock to aquatic organisms such as fish have been created in man's quest for energy in recent decades. The critical sites are steam-operated electrical power stations, either nuclear- or fossilfueled, that dissipate waste heat via once-through cooling into freshwater, estuarine and marine areas.

Effects from heated discharges are related to the thermal increment $(\Delta T)$ imparted to cooling water by power plant condensors. In Europe, temperatures are generally increased by plant operation 7.5 to $11^{\circ} \mathrm{C}$ at freshwater locations and 12.0 to $16.0^{\circ} \mathrm{C}$ at saltwater sites. In the United States, the average maximum rise from power reactors is $10.8^{\circ} \mathrm{C}$, while the range is from 5.6 to $18.0^{\circ} \mathrm{C}$ (Coutant, 1970).

The effects of elevated temperatures from power plant operation are well known, and various models of thermal plume dispersal are available (e.g., Ackers, 1969; Stolzenbach, Adams and Harleman, 1973). However, the impact of cold shock from station shutdown, whether due to scheduled maintenance or system malfunction, has received less attention. In such cases, fish in heated discharge areas undergo sublethal or lethal cold shock from rapid temperature declines. The threat is very real (Cairns, 1972), although relatively few cases causing mass mortality of fish populations have been well documented (Anon. 1971, 1972; Ash, Chymko and Gallup, 1974; Clark and Brownel1, 1973).

This paper: 1) presents some basic data derived from the literature on the resistance of fish to cold, 2) illustrates use of thermal resistance data for evaluating direct impact of cold shock after power plant shutdown, and 3) describes a simplified analytical approach for estimating the decline rate of a thermal plume associated with an offshore discharge in lakes, reservoirs, cooling ponds, and coastal areas. 


\section{BASIC COLD SHOCK DATA}

The features underlying heat and cold resistance in fish and other aquatic poikilotherms are similar. Only the direction of temperature change differs. These features are briefly reviewed to provide a background for predicting cold shock impacts.

Thermal Resistance

Resistance to increasing or decreasing temperatures depends primarily on thermal history, where an organism is adapted to a given temperature regime, and on the range of subsequent temperature change. For experimental purposes, thermal history is represented by the acclimation temperature and assumes physiological adaptation.

According to classical thermal resistance concepts, cold-blooded organisms have a central "zone of thermal tolerance" where survival is indefinite regardless of temperature alteration. The tolerance zone is bordered by the upper and lower "zones of thermal resistance" where mortality can occur. The inner boundaries of the resistance zones represent the upper and lower "ultimate incipient lethal limits" (Coutant, 1970, 1972a; Brett, 1970; Fry, 1967; Fry, Hart and Walker, 1946). Tolerance and resistance zones are genetically related to, and characteristic of, each species. However, response to temperature changes as well as the resistance and lethal limits can be modified by such factors as behavior, body size, season, photoperiod, sex, water chemistry, diet, hormone balance, salinity, disease and various stresses.

Boundaries of the thermal resistance zones vary with acclimation temperature, which is a seasonal phenomenon in nature. Thus, heat resistance shifts upward in the summer and downward in the winter, while cold resistance changes inversely. Survival from exposure to any extreme shift in temperature entering the upper or lower resistance zone depends upon the range of temperature change and duration of exposure. If the change falls near but beyond the incipient lethal limit, mortality occurs only after prolonged exposure. If the change is considerably greater, mortality occurs almost instantly (Coutant, 1970). 
Basic thermal resistance parameters can be determined with precision in laboratory tests with fish (and other aquatic organisms) where acclimation and test temperature are the two major variables. The obtained lethal temperature is usually a central statistic, defined by either loss of equilibrium (LE) or death ( $D$ ) of haif the test organisms. When death is the parameter, the temperature where $50 \%$ mortality $\left(\mathrm{TL}_{\mathrm{m}}\right)$ occurs is the median incipient lethal temperature, based on the original acclimation level. The most extreme, upper and lower, temperatures possible by acclimation establish the ultimate incipient lethal limits.

The incremental temperature imparted by a heated discharge is equivalent to thermal history of the species, but not necessarily to acclimation temperature. This assumes that organisms in the discharge area have sufficient exposure to become adapted to the incremental temperature, hence, acclimation. Also, the ambient temperature is the cooler regime prevailing beyond the mixing zone. Return to ambient imparts gradual or abrupt cold shock, depending on cooling rate.

Application of Cold Resistance Data

A lower temperature tolerance diagram applicable for a hypothetical cold-blooded organism is shown in Figure 1 , where the diagonal lines are regressions of ambient on incremental temperatures. In theory, the thermal tolerance zone lies above the solid diagonal line and the thermal resistance zone below it. Any combination of ambient and incremental temperature falling above will not impart direct mortality from cold shock, whereas any combination falling below will cause mortality, given sufficient exposure time.

Suppose a schooi of fish with cold tolerance illustrated in Figure 1 inhabited an area heated above $25^{\circ} \mathrm{C}$ and, for some reason, the water suddenly returned to ambient at $4^{\circ} \mathrm{C}$. Total mortality from cold shock is assured. However, all fish would survive if ambient was actually $8^{\circ} \mathrm{C}$. The situation is less clear if the intersection falls near the diagonal 1 ine representing the median tolerance limit $\left(T L_{m}\right)$ where, theoretically, 50\% of the fish will die. 


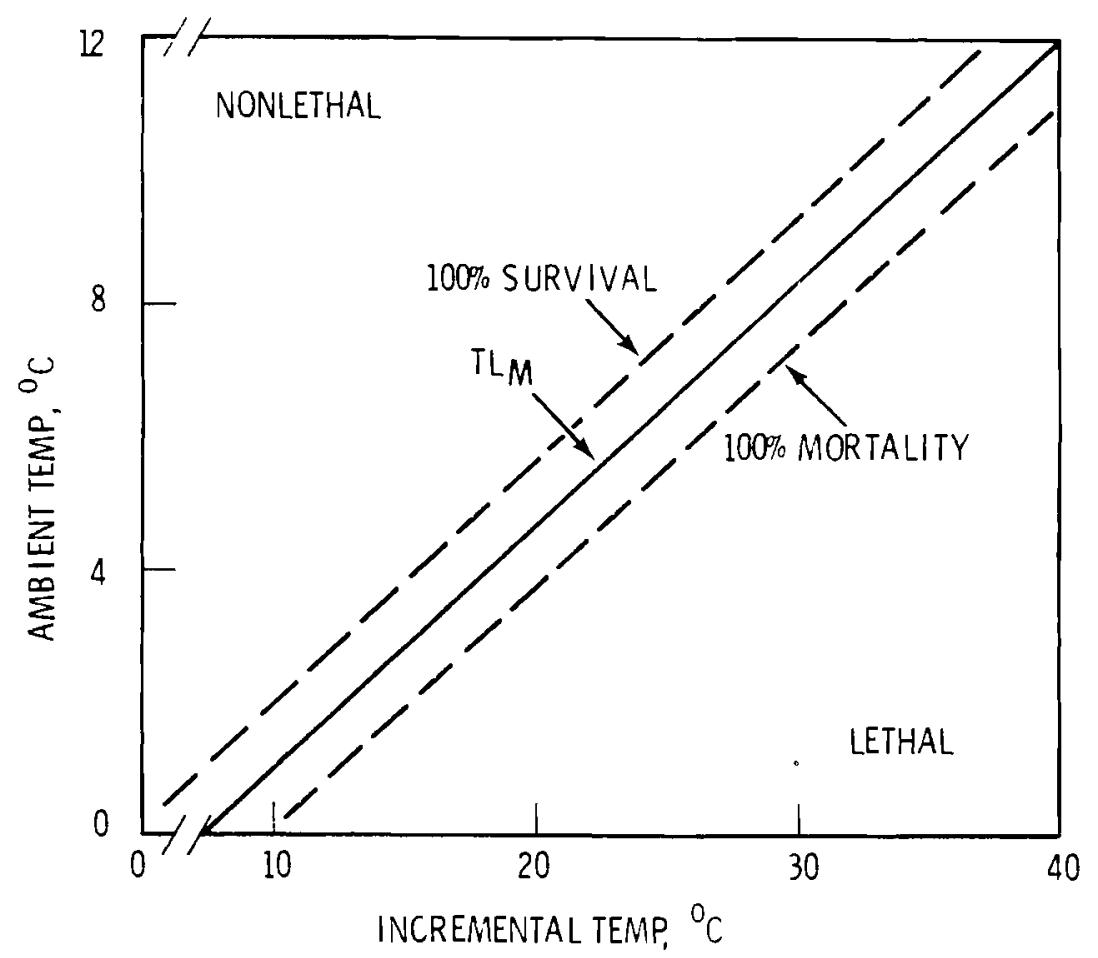

FIGURE 1. Lower temperature tolerance diagram for a hypothetical cold-blooded aquatic organism. Combinations of ambient and incremental temperatures providing nonlethal and lethal exposures are indicated.

Selected data from the literature on resistance of freshwater and marine fish to cold are illustrated in Figures 2 and 3 , where the data points are $50 \%$ mortality levels. The regressions are not necessarily linear. Temperatures near maximum for acclimation, which vary among species, are to the right. Lower lethal threshold temperature data for other species of aquatic organisms at different acclimations are summarized in Appendix II-C of Water Quality Criteria 1972 (Committee on Water Quality Criteria, 1973) and by Coutant (1972b).

These data exemplify the information required to predict direct impact of cold shock in mixing zones resulting from power plant shutdown. Incremental and ambient temperatures, although varying, are usually known in 


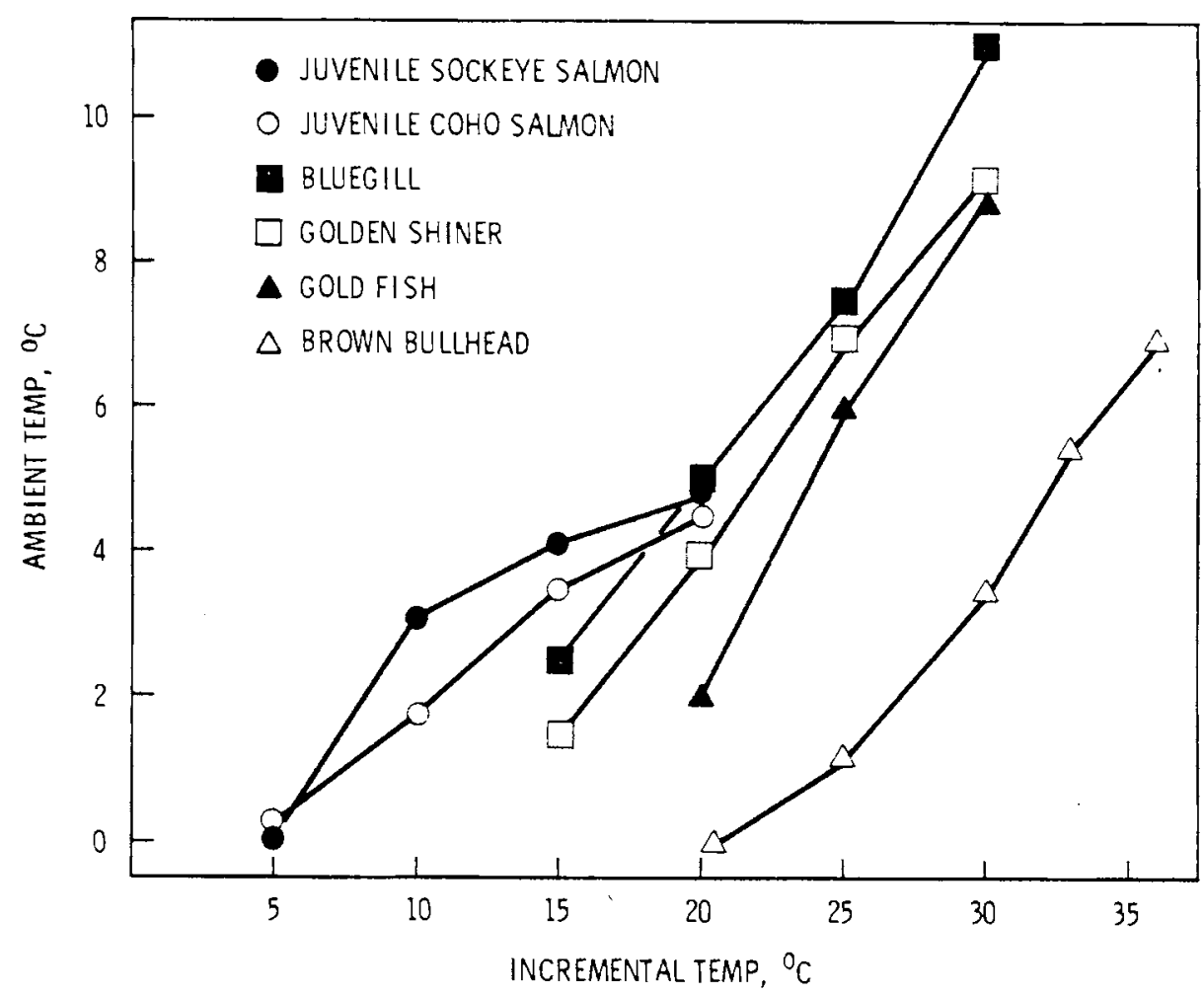

FIGURE 2. Resistance of selected freshwater fish to cold, based on declines from incremental (acclimation) to natural (ambient) temperatures: sockeye salmon (Oncorhynchus nerka), cono salmon ( 0 . kisutch), bluegill (Lepomis macrochirus), golden shiner (Notemigonus crysoleucas), goldfish (Carassius auratus), and brown bu17head (Ictalurus nebulosus). (Drafted from data compiled by Brett, 1956.)

advance. In some cases, plant shutdown may be controlled in time or completeness to eliminate, or at least greatly reduce, the possibility of cold shock mortalities among localized fish populations.

The consequence of abrupt power plant (fossil-fuel) shutdown was recently described in Lake Wabamum, Alberta, Canada (Ash et al., 1974). A fish kill occurred in early February, 1973 when mechanical failure forced plant closure and the temperature in an extended discharge canal dropped $16.9^{\circ} \mathrm{C}$ (from 21.8 to $4.9^{\circ} \mathrm{C}$ ) in a 30 min span (Figure 4). About 250,000 spottail shiner (Notropis hudsonius) and 250 northern pike (Esox lucius) were destroyed by the sudden onset of cold. 


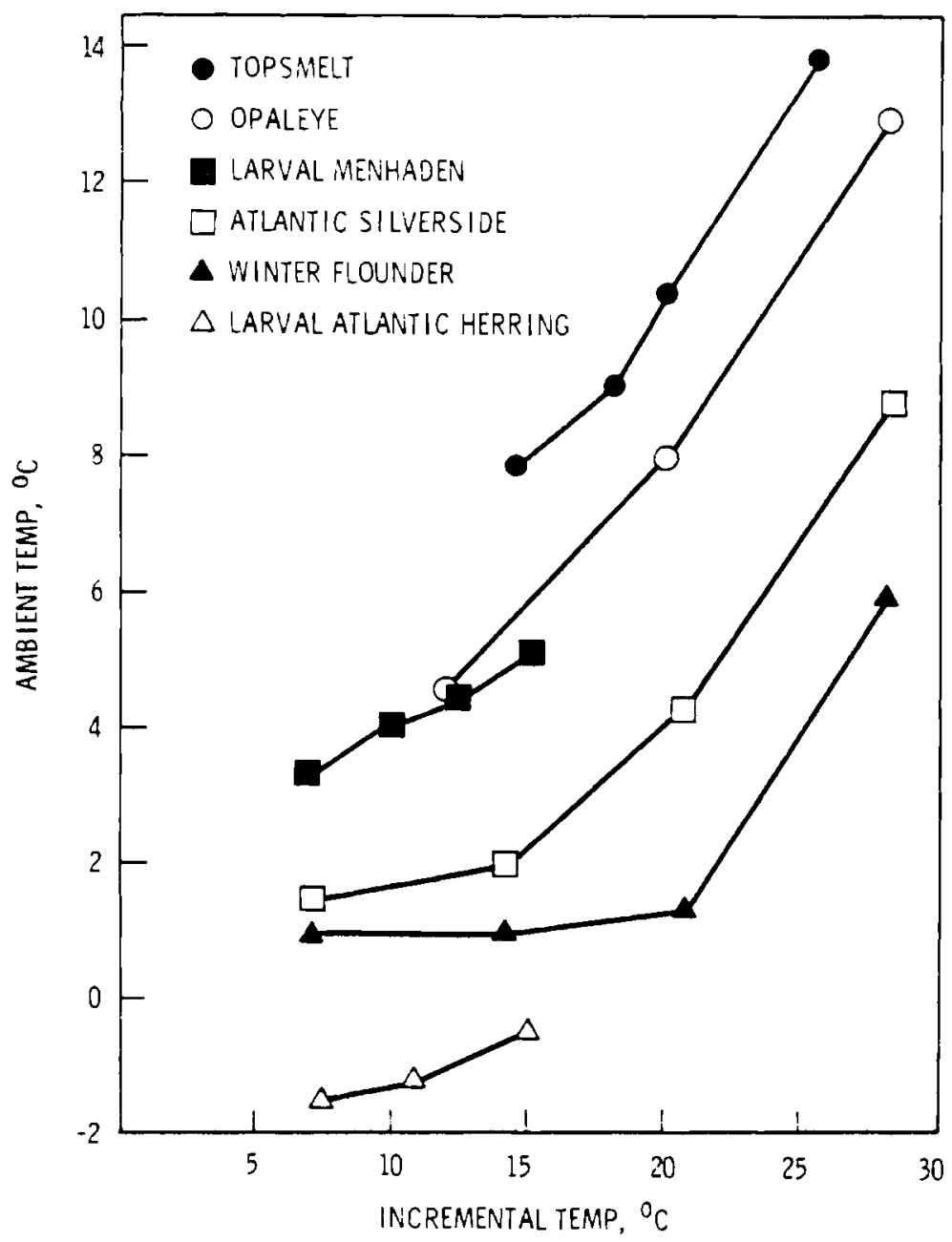

FIGURE 3. Resistance of selected marine and estuarine fish to cold, based on decline from incremental (acclimation) to natural (ambient) temperatures: topsmelt (Atherinops affinis), opaleye (Girella nigricans), menhaden (Brevoortia tyrannus), Atlantic silverside (Menidia menidia), winter flounder (Pseudopleuronectes americanus) and Atlantic herring (Clupea harengus). (Drafted from data compiled by Brett, 1970.) Note: resistance may vary with salinity.

Bioassay data on cold resistance of spottail shiner are unavailable. But, when acclimated to $20^{\circ} \mathrm{C}$, the lower incipient lethal temperature for common shiner ( $\underline{\mathbb{N}}$. cornutus) and emerald shiner ( $\underline{N}$. atherinops), are 3.7 and $5.2^{\circ} \mathrm{C}$, respectively (Hart, 1947). No data are available for northern pike. If cold resistance in spottail shiner is simiiar to its two related species, the lethality of such an extreme temperature decline as in Figure 4 was inevitable and predictable. 


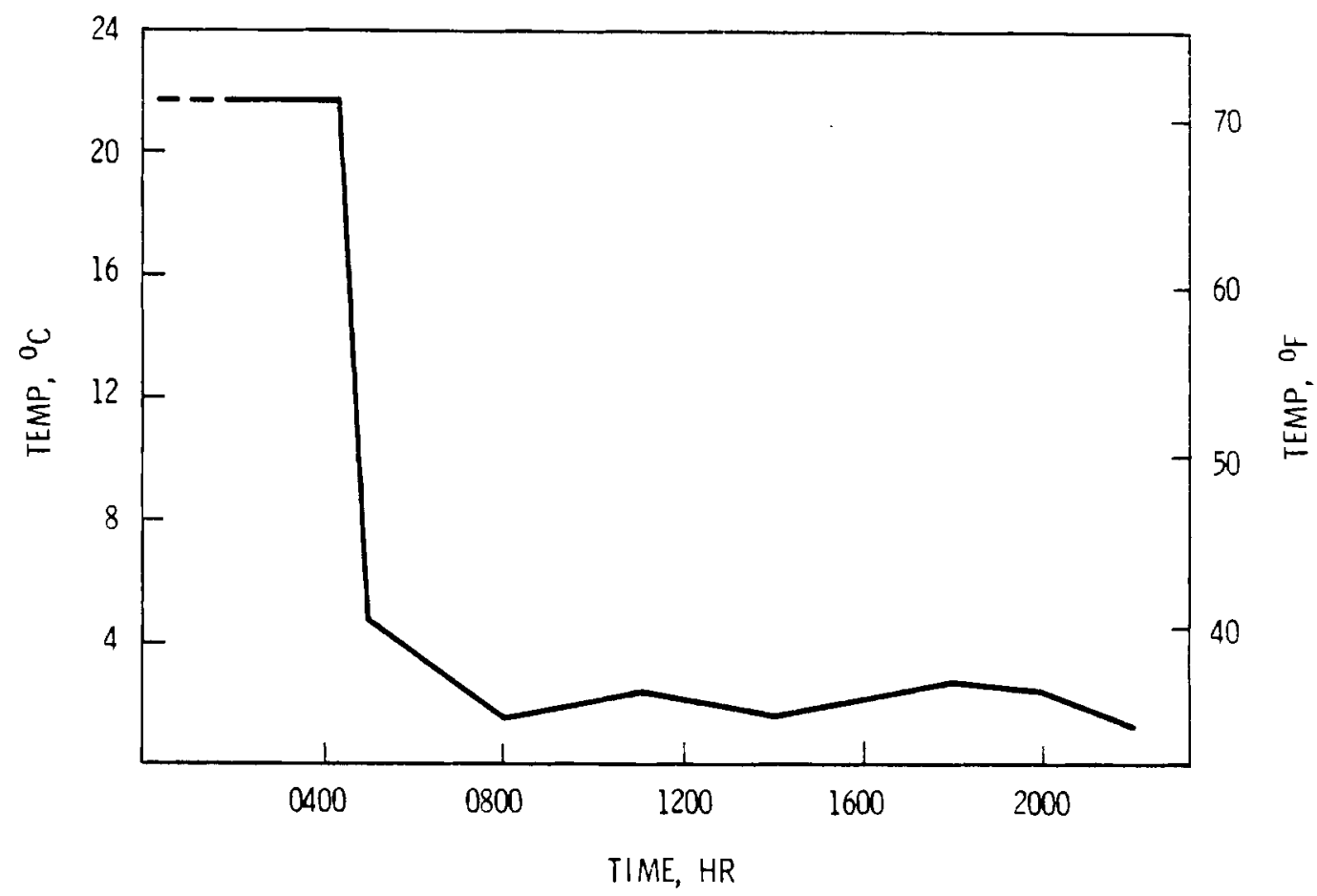

FIGURE 4. Temperature decline in a cooling water discharge canal at the Sundance Plant, Lake Wabamum, Alberta, Canada after shutciown on February 8, 1973. (From Ash et al., 1974; reproduced with permission.)

A comparable cold shock kill in a riverine situation occurred at Brunner's Island, in the Susquehanna River, Pennsylvania, when a power station (also fossil-fuel) was forced to terminate operation in early February, 1971. The temperature in the mixing zone dropped from 25.7 to $2.2^{\circ} \mathrm{C}$. An estimated 15,388 "valued" fish congregating in the warmer water were destroyed (Anon., 1971; Cairns, 1972). The fish involved were walleye (Stizostedion vitreum), smal lmouth bass (Micropterus dolomieui), muskellunge (Esox masquinongy), northern pike, and various panfish, catfish and suckers. An additional 7,790 carp (Cyprinus carpio) also died.

Effect of Gradual Temperature Declines

Data from abrupt cold shock tests can be used to predict direct mortality of aquatic organisms in most situations, but may be unnecessarily conservative where temperature declines occur gradually. 
The rate of heat dissemination is reduced at many lakes, reservoirs, cooling ponds and coastal sites where water movement is restricted. If the organism is mobile (as are fish) and leaves the discharge area, it immediately encounters ambient temperature and receives maximum exposure to cold. But if the organism remains in the discharge area, it experiences a gradual temperature decline over a period of hours or days. The eventual consequences of cold shock are then reduced.

Partial metabolic acclimation by cold blooded organisms to falling temperatures can occur when temperature decline rates are gradual so that the lower lethal limit is, itself, lowered. Thus, some protection is gained against the terminal cold regime. Any reduction in the lower lethal limit by gradual cooling may mean the difference between death or survival to part or all of the affected population.

Cold-blooded organisms generally acclimate more slowly to cold than to heat, but partial acclimation provides enhanced ability to cope with rapid changes that lie within the ultimate lethal level (Brett, 1970; Fry, 1967). Capacity to "compensate" for directional temperature changes over a brief span of hours or days is not well known. Whenever temperature alterations occur, upwards or downwards, acclimation processes are almost certainly working. Compensation undoubtedly varies with species, initial acclimation level, and other factors. However, compensation basically depends on the rate of temperature change, and becomes most effective under the more gradual rates.

Temperature change rates permitting survival of bluegill sunfish (Lepomis macrochirus) have been examined experimentally (Speakman and Krenkel 1972). Rates of increase causing mortality were at least 20 times as rapid as corresponding rates of decrease, indicating that compensation was much more rapid for increasing than decreasing temperatures. Decline rates providing 50 and $99 \%$ survival during cooling were: 1) -0.19 and $-0.15^{\circ} \mathrm{C} / \mathrm{hr}$ for $25 \rightarrow 5^{\circ} \mathrm{C}$ range, 2) -0.072 and $-0.053^{\circ} \mathrm{C} / \mathrm{hr}$ for $30 \rightarrow 5^{\circ} \mathrm{C}$ range, and 3$)-0.32$ and $-0.16^{\circ} \mathrm{C} / \mathrm{hr}$ for $30 \rightarrow 10^{\circ} \mathrm{C}$ range, respectively. If exposure from each higher acclimation level was abrupt, imparting instantaneous cold shock, the lower terminal temperatures of 10 and $5^{\circ} \mathrm{C}$ would have proven lethal (Figure 2). 


\section{MODEL ING TEMPERATURE DECLINES IN A TRANSIENT PLUME}

Modeling temperature declines in thermal plumes during power plant assessment studies becomes important whenever temperatures are gradually reduced by site-specific hydrological conditions following plant shutdown. Effects of abrupt temperature declines can be evaluated directly from basic cold shock data (Figures 1,2 and 3 ). However, effects of gradual temperature declines can be evaluated more precisely from predicted cooling rates in mixing zones.

The following is a simplified analytical approach, based on classical theory, for estimating decay of thermal plumes originating from an offshore discharge. The results appear valid for any situation where there is minimum influence from shearing currents and confining shorelines.

Rationale

The thermodynamic behavior of a declining thermal plume is inherently time-dependent, three-dimensional, nontinear and complicated by phenomena such as turbulence, surface heat transfer and buoyancy. Boundary conditions such as shoreline geometry and meteorological conditions introduce further complexity in plume behavior. Ideally, the complete equations of timedependent turbulent motion and coupled thermal energy transport in three dimensions would be solved with the aid of a high-speed digital computer to arrive at a rational, space-time temperature projection of plume decay.

However, this laborious task involves large amounts of computer time and considerable expense. A much simpler approach can frequently be taken that, al though not as precise, will produce satisfactory resuits for many predictive purposes. The approach relies heavily on the expertise and judgment of the analyst to construct simplistic conditions that will reasonably simulate, or at least "bracket" actual conditions. 
Modeling Plume Decline

Equations describing the motion and thermal character of a heated water plume are based on three conservation laws of physics:

- conservation of mass

- conservation of momentum

- conservation of energy

Additionally, an equation of state that relates fluid density and temperature is required. For an incompressible turbulent flow, these equations can be stated in mathematical form as

- conservation of mass

$$
\frac{\partial u_{i}}{\partial x_{i}}=0
$$

- conservation of momentum

$$
\frac{\partial u_{i}}{\partial t}+\frac{\partial u_{j} u_{i}}{\partial x_{j}}=-\frac{\partial p \star}{\partial x_{i}}+\left(\frac{\rho_{0}-\rho}{\rho_{0}}\right) g \delta_{i 3}+\varepsilon^{\prime} \frac{\partial^{2} u_{i}}{\partial x_{j} \partial x_{j}}
$$

- conservation of energy

$$
\frac{\partial T}{\partial t}+\frac{\partial^{u_{i} T}}{\partial x_{i}}=\varepsilon \frac{\partial^{2} T}{\partial x_{i} \partial x_{i}}+\dot{Q}
$$

- state

$$
\rho=\rho(T)
$$

where summation subscript notation is used. Nomenclature in the above equations is as follows:

$$
\begin{aligned}
x_{i} & =i^{\text {th }} \text { space coordinate } \\
u_{i} & =\text { velocity component along } i^{\text {th }} \text { space coordinate } \\
t & =\text { time } \\
p^{*} & =\text { deviatoric pressure } \\
\rho, \rho_{0} & =\text { density (subscript } 0 \text { indicates reference value of the source) } \\
g & =\text { gravitational constant }
\end{aligned}
$$




$$
\begin{aligned}
\varepsilon^{\prime} & =\text { turbulent diffusion coefficient for momentum } \\
\varepsilon & =\text { turbulent diffusion coefficient heat } \\
T & =\text { temperature } \\
\dot{Q} & =\text { heat source or sink } \\
\delta_{i k} & =\text { kronecker delta function }
\end{aligned}
$$

The transport coefficients $\varepsilon^{\prime}$ and $\varepsilon$ are assumed to be constant to simplify the equations. Also, considerable simplification is introduced if Equations 2 and 3 are decoupled, and it is assumed that $u(x, y, z, t)$ is known a priori. Thus, we need only solve Equation 3 to compute the space-time thermal history of the plume. The computations will be valid if buoyant interaction has a minor influence on plume motion.

Under these conditions, the appropriate equation for heat transport may be written in rectilinear coordinates as

$$
\frac{\partial T}{\partial t}+\frac{\partial u T}{\partial x}+\frac{\partial v T}{\partial y}+\frac{\partial W T}{\partial z}=\varepsilon_{x} \frac{\partial^{2} T}{\partial x^{2}}+\varepsilon_{y} \frac{\partial^{2} T}{\partial y^{2}}+\varepsilon_{z} \frac{\partial^{2} T}{\partial z^{2}}+\dot{Q}
$$

where

$$
\begin{aligned}
T= & \text { water temperature } \\
u, v, w= & \text { velocity components in the receiving water along the } \\
& x, y \text { and } z \text { directions, respectively } \\
\varepsilon_{x}, \varepsilon_{y}, \varepsilon_{z}= & \text { diffusion coefficients along the } x, y \text { and } z \text { directions, } \\
& \text { respectively }
\end{aligned}
$$

Equation 5 can be solved using finite-difference or Lagrangian-random walk techniques implemented on a digital computer, provided the velocity field, diffusion coefficients, heat sources or sinks, and initial and boundary conditions are known. However, considerable time and expense would still be required in execution of this solution procedure.

Further simplification can be employed while still maintaining a useful result if the velocity field is assumed to be unidirectional and uniform in 
space. Therefore, $u=u_{0}(t), v=0$ and $w=0$, the diffusion coefficients were assumed to be constant in space and time, and $\varepsilon_{x}=\varepsilon_{y}=\varepsilon_{l} \neq \varepsilon_{z}$. Thus,

$$
\frac{\partial T}{\partial t}=\varepsilon_{\ell}\left(\frac{\partial^{2} T}{\partial x^{2}}+\frac{\partial^{2} T}{\partial y^{2}}\right)+\varepsilon_{z} \frac{\partial^{2} T}{\partial z^{2}}+\dot{Q}
$$

where the coordinate system moves according to

$$
d x=u_{0}(t) d t
$$

Equation 6 has a form identical to the heat conduction equation for a heat generating, anisotropic media and, for various boundary and initial conditions, can be solved using classical methods (cf. Carslaw and Jaeger, 1959). A similar approach has been applied for one-dimensional cooling of thermal plumes in well-mixed rivers and estuaries (Pilati, 1973).

Many heat transfer computer codes are available that could be employed for numerical simulation in cases where an analytical solution is difficult or impossible using known techniques. Therefore, we will not delve into techniques of numerical simulation, but will explore conditions that permit analytical solution. In this regard, we set $\varepsilon_{z}=0$ (no vertical diffusion) and assume $Q$ is proportional to atmospheric heat exchange. Hence, the heat transport equation has the form

$$
\frac{\partial \theta}{\partial t}=\varepsilon_{\ell}\left(\frac{\partial^{2} \theta}{\partial x^{2}}+\frac{\partial^{2} \theta}{\partial y^{2}}\right)-\alpha \theta
$$

where

$$
\begin{aligned}
\theta \quad & \frac{T-T_{r}}{T_{0}-T_{r}}, \text { dimensionless temperature } \\
T_{0}, T_{r}= & \text { reference temperatures of the plume: The maximum plume } \\
& \text { temperature and ambient, respectively } \\
\alpha \quad= & K_{S} / C D \\
K_{S} \quad= & \text { surface exchange coefficient } \\
C \quad= & \text { volumetric specific heat } \\
D \quad= & \text { depth of the thermal plume. }
\end{aligned}
$$


The simplified heat equation (8) may be solved analytically, or at least closed to an integral form, for any initial temperature condition $F(x, y)$. Cylindrical coordinates are more convenient for most cases, and will yield the diffusion equation for symmetric conditions .

$$
\frac{\partial \theta}{\partial t}=\frac{\varepsilon_{\ell}}{r} \frac{\partial}{\partial r}\left(r \frac{\partial \theta}{\partial r}\right)-\alpha \theta
$$

Analytical Solution and Results

The solution to Equation 9 is given by

$$
\theta(r, t)=\frac{e^{-\alpha \theta}}{2 \varepsilon_{l} t} \int_{0}^{\infty} e^{-\left(r^{2}+R^{2}\right) / 4 \varepsilon_{2} t} I_{0}\left(\frac{r R}{2 \varepsilon_{2} t}\right) F(R) R d R
$$

where

$I_{0} \quad=$ modified Bessel function of zero ${ }^{\text {th }}$ order

$F(R)=$ initial temperature distribution.

The heat equation (10) cannot be simplified to obtain a general solution in terms of elementary functions, but can easily be solved by numerical integration.

Accordingly, a computer program was prepared to provide solutions for an arbitrary function $F(R)$. Three different initial distributions were analyzed as follows:

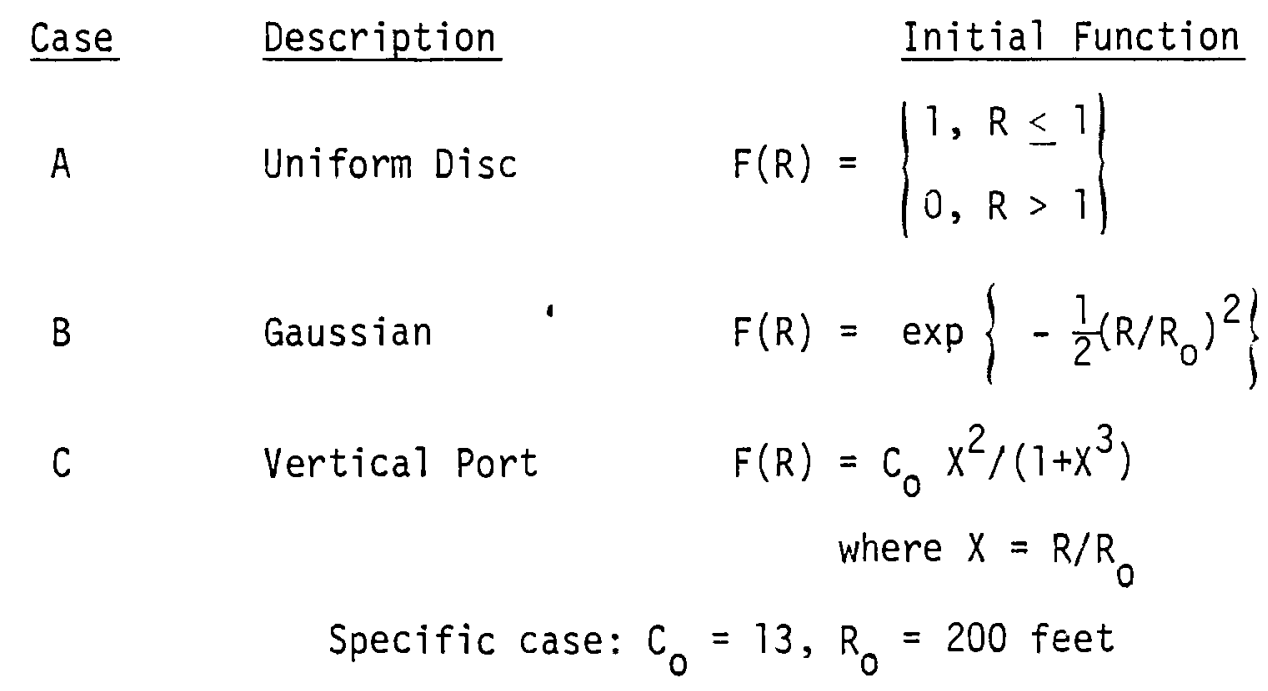


In the above three cases, $R_{0}$ is a characteristic radius of the initial plume (Figure 5). It is important to note that these three cases are presented only as examples, and are not meant to represent the same quantity of thermal energy in each case.

Selecting an initial function yielding results that actually represent the thermal decline in a heated discharge plume is a decision for the analyst. The choice must be made on a case-by-case basis because hydrologic conditions in receiving waters vary from site to site, and sometimes seasonally at a given site. The selected function should provide conservative results, yet not be so conservative that the derived data are meaningless.

The Uniform Disc (Case A) represents an initial function that should give "worst case" results (i.e., maximum rate of temperature decay). The Gaussian function (Case B) perhaps represents a more realistic initial function and should give less conservative results than the Uniform Disc approximation.

Case $C$ represents a specific initial function for a Vertical Port discharge in shallow water. Steady discharge of heated water in Case $\mathrm{C}$ will attain a surface distribution of the approximate form

$$
\theta \sim f\left(\frac{1}{R}\right)
$$

If this distribution is achieved during station operation and the discharge is abruptly ceased, inertia of the lateral spread will cause momentary upwelling of cold water at the plume center. Hence, the initial function wiil achieve a distribution essentially similar to Case C (Figure 5). This function was chosen to illustrate application of the analys is to shapes more complex than $A$ or $B$. Thus, functions other than given by Cases $A$ or $B$ might be chosen, depending on the initial temperature distribution expected.

Time-temperature histories for test Cases $A, B$ and $C$ are illustrated in Figures 6-11, where representative values of the parameters $R_{0}, \varepsilon_{l}$ and $K_{S}$ are used. 


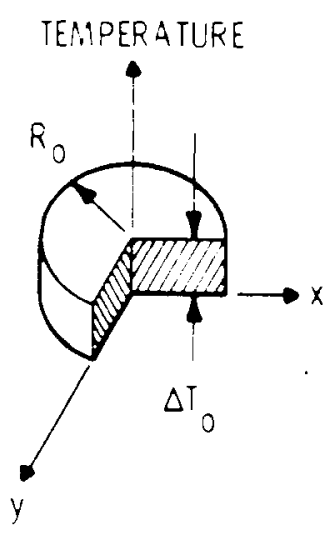

CASE A: DISC

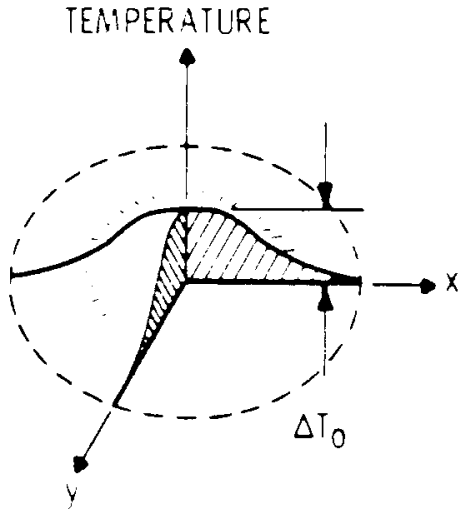

CASE B: GAUSSIAN

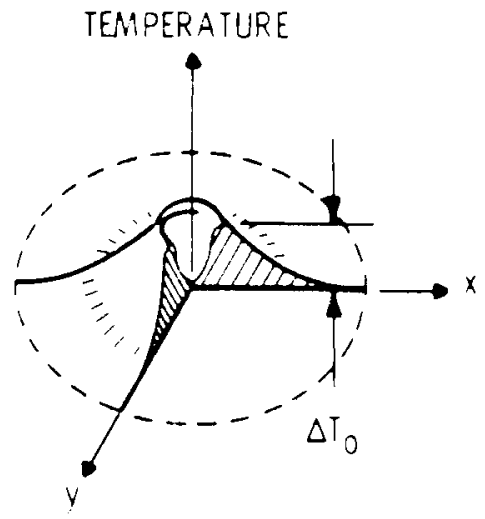

CASE C: VERTICAL PORT

FIGURE 5. Plume decay model, initial analytical conditions for Cases $A, B$ and $C$.

Dimensionless temperature profiles, defined by the ratio $\theta=\left(T-T_{r}\right) /$

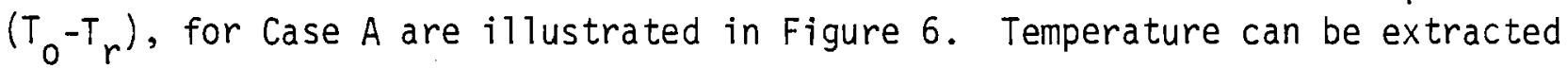
by solving for $T$ to obtain $T=T_{r}+\theta\left(T_{0}-T_{r}\right)$. Profiles are plotted as a function of normalized radial distance $R / R_{0}\left(R_{0}\right.$ is the initial radius of the plume) for various values of the dimensionless parameter $\xi=\varepsilon t / R_{0}^{2}$ and an atmospheric heat exchange parameter $\alpha=0.015 \mathrm{hr}^{-1}$. The value of $\alpha$ used in this case corresponds to a surface heat transfer coefficient $K_{s}=57 \mathrm{~W} / \mathrm{m}^{2}-{ }^{\circ} \mathrm{C}$ and a typical plume depth of approximately $3.5 \mathrm{~m}$. The value of $\mathrm{K}_{\mathrm{s}}$ used represents a maximum value for most situations and was chosen to maximize the atmospheric contribution to the rate of temperature decay.

Figure 7 illustrates the effect of atmospheric heat exchange on the rate of temperature decay for a specific situation where $\varepsilon=1 \mathrm{~m}^{2} / \mathrm{sec}$ and $R_{0}=$ $300 \mathrm{~m}$.

Similar information is conveyed by Figures 8 and 9 for a plume with a Gaussian initial profile, Case B. Results for Case $C$ are illustrated in Figures 10 and 11 . As mentioned earlier, these results are for a specialized situation, hence, are not given in dimensionless form. 


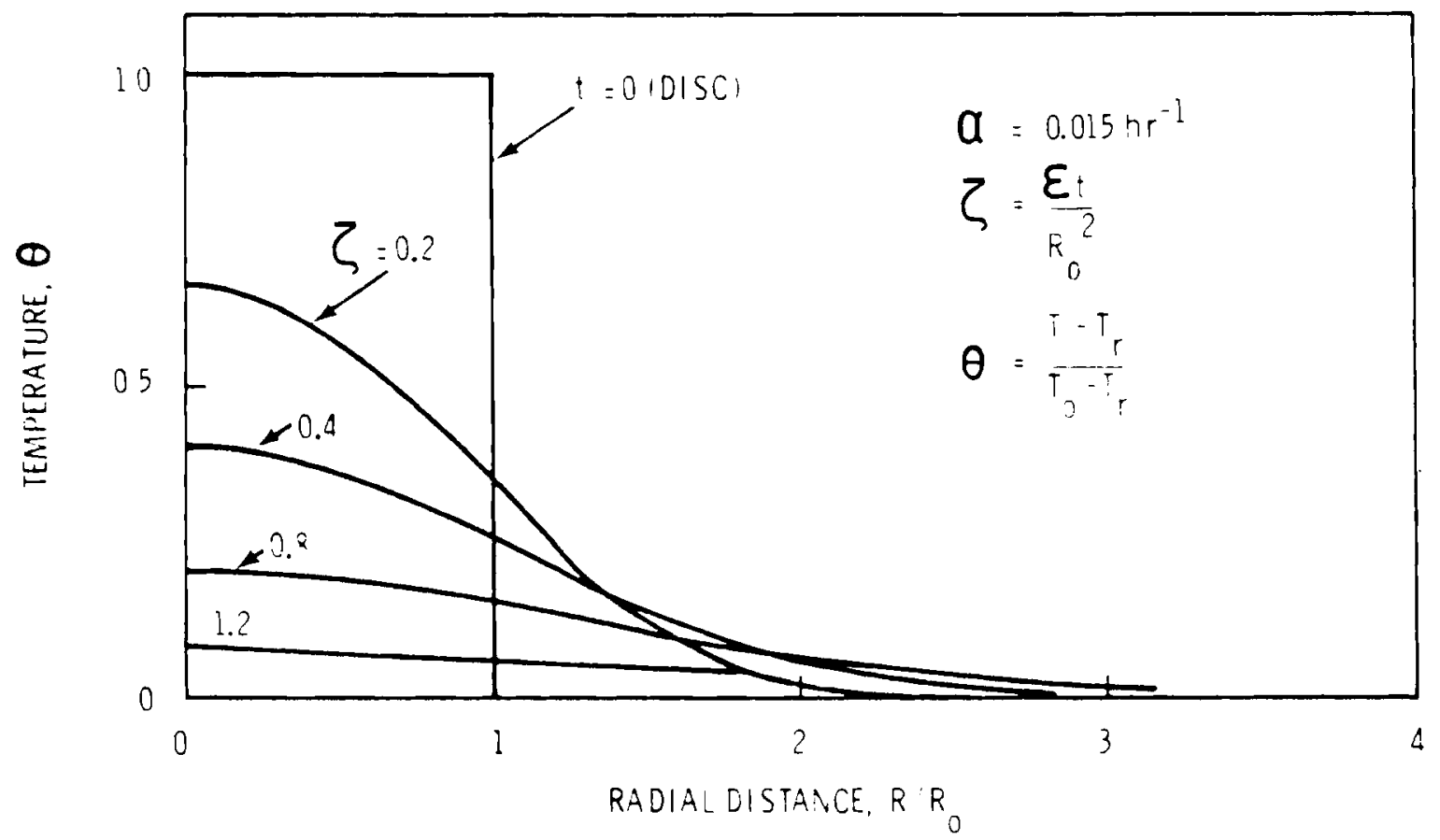

FIGURE 6. Case A. Radial temperature distribution, Uniform Disc.

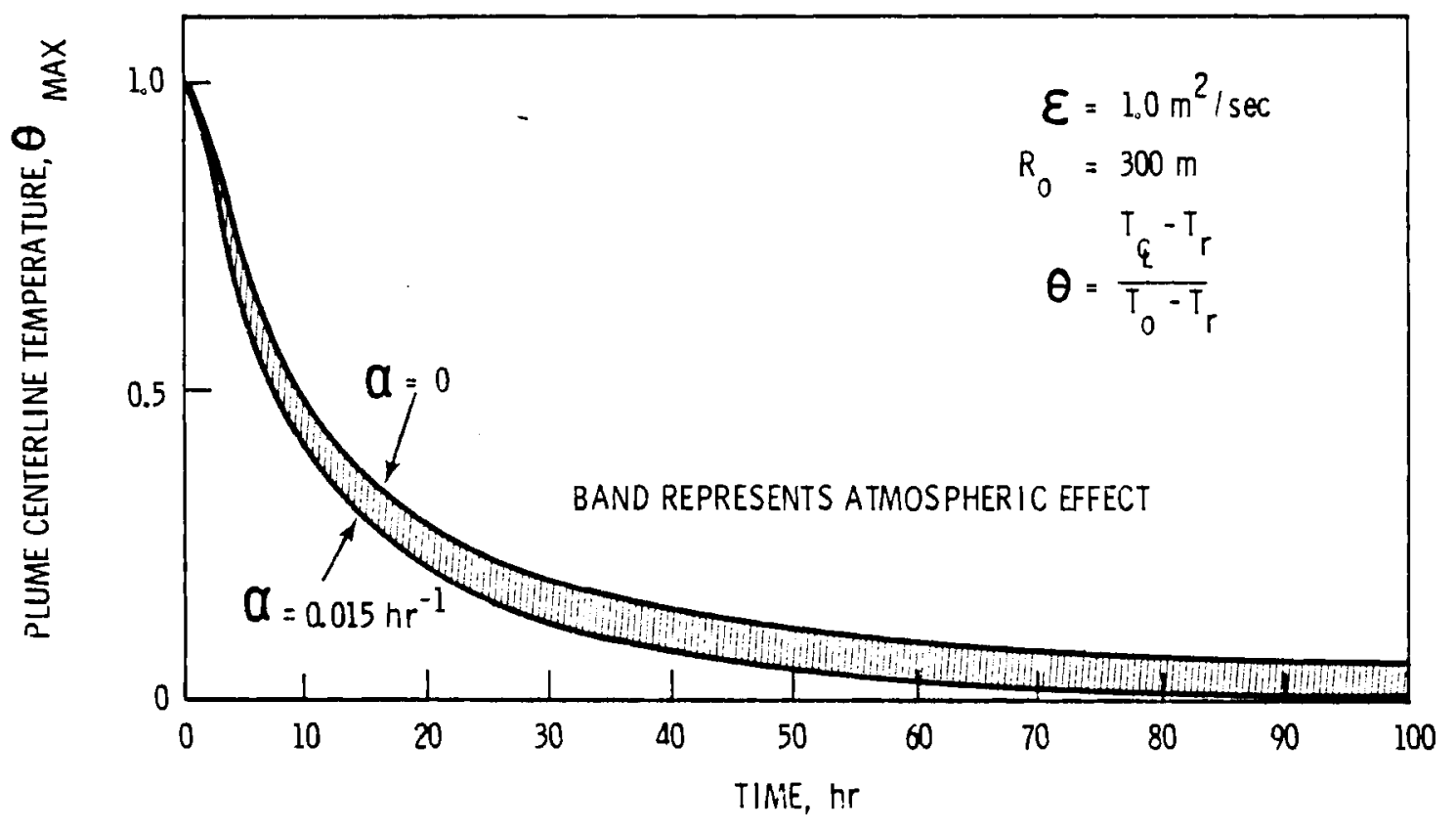

FIGURE 7. Case A. Decay rate of maximum (centerline) temperature, Uniform Disc. 


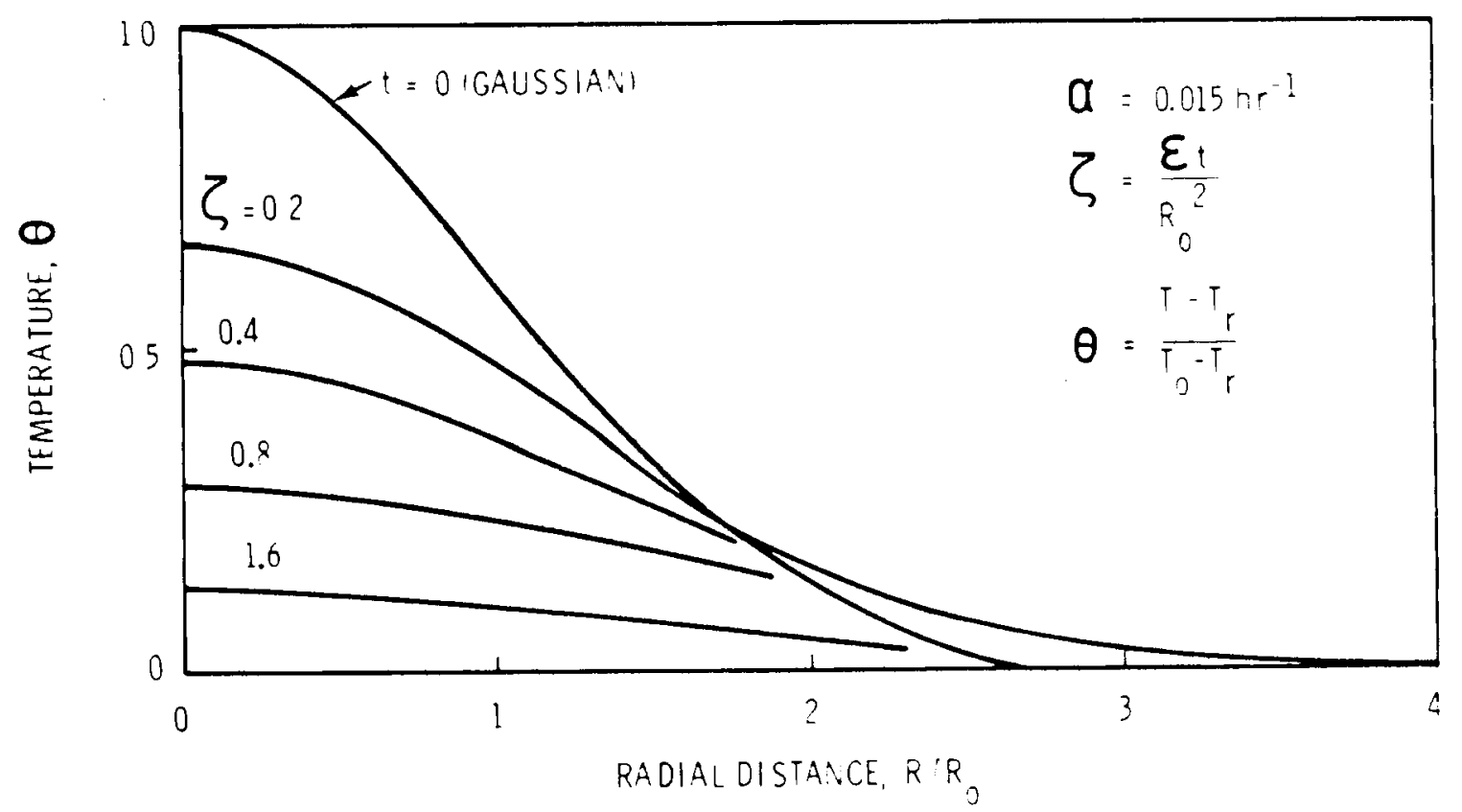

FIGURE 8. Case B. Radial temperature distribution, Gaussian.

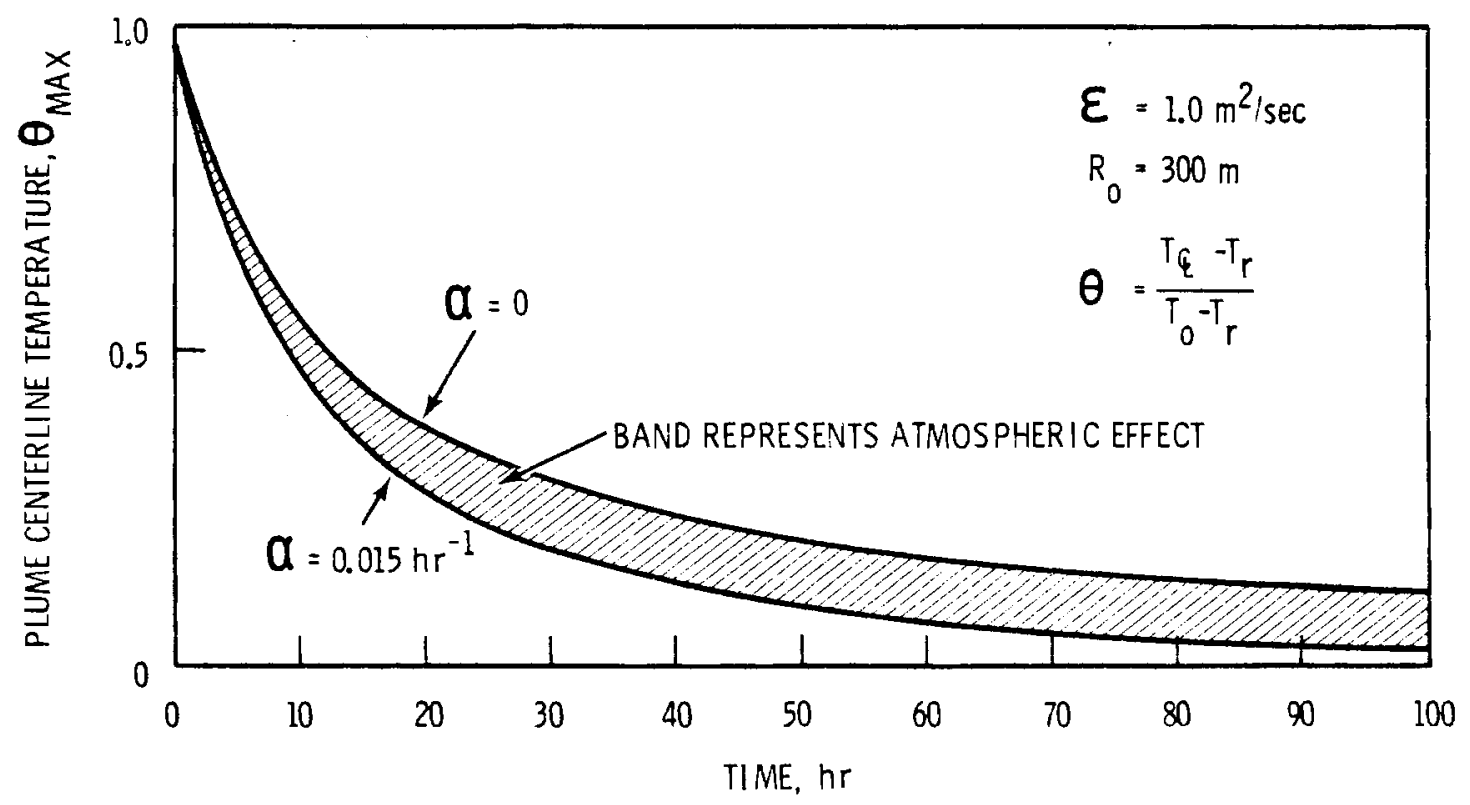

FIGURE 9. Case B. Decay rate of maximum (centerline) temperature, Gaussian. 


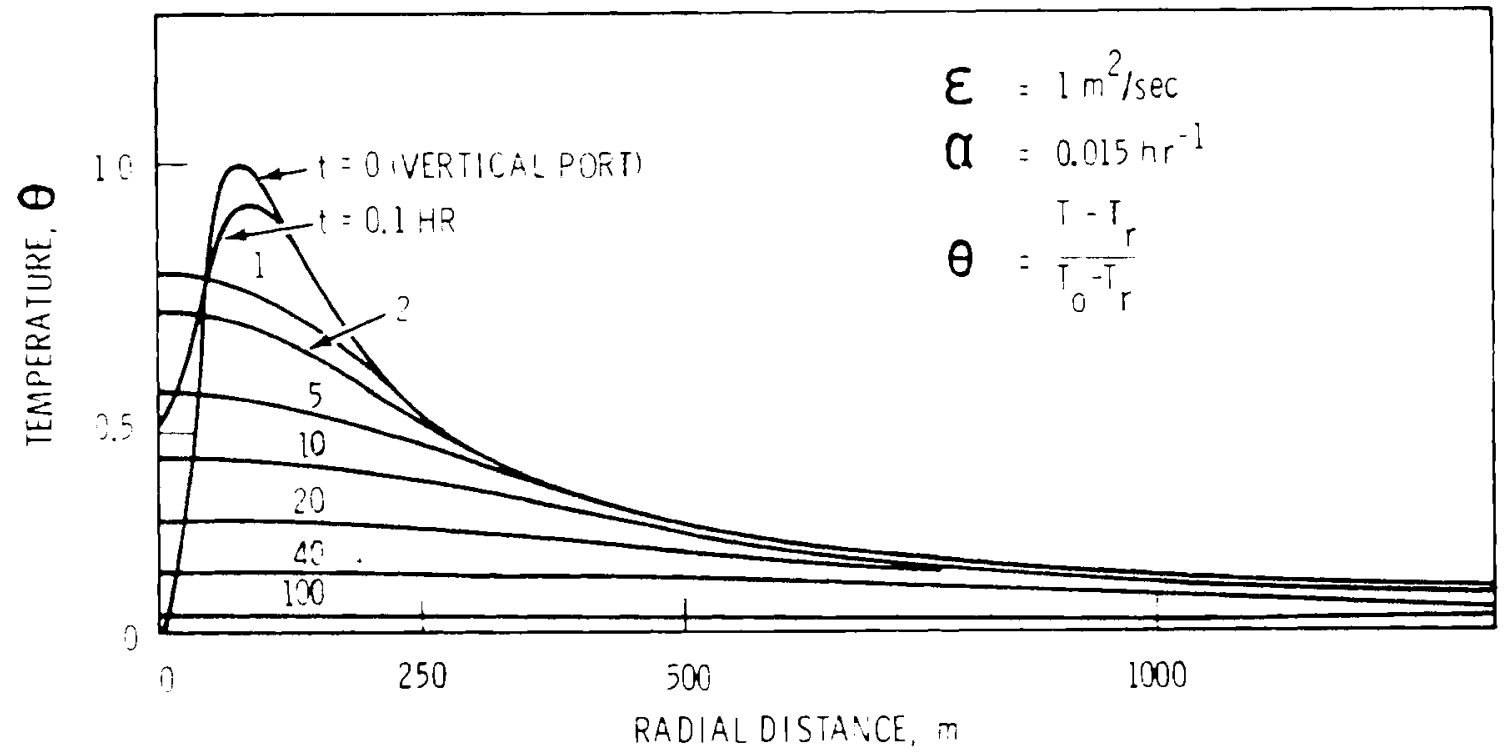

FIGURE 10. Case C. Radial temperature distribution, Vertical Port.

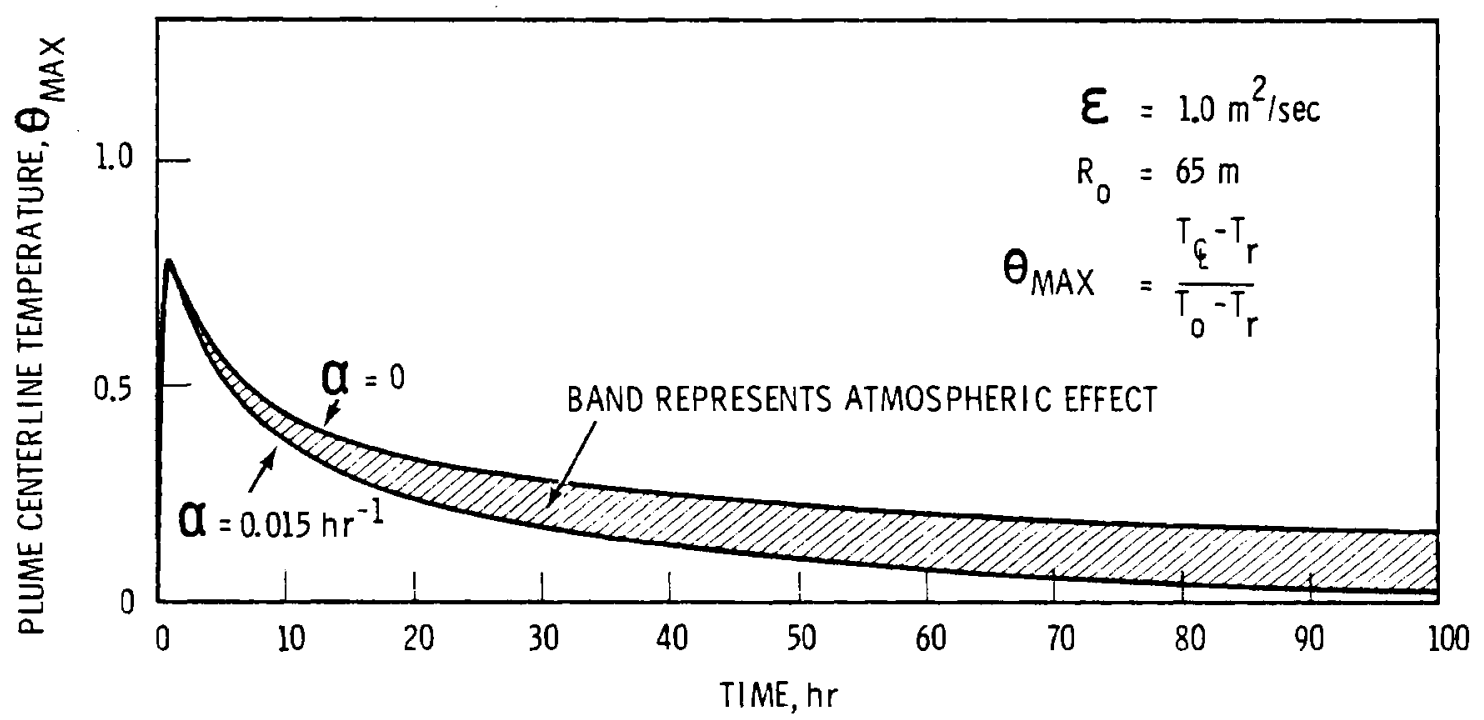

FIGURE 11. Case C. Decay rate of maximum (centerline) temperature, Vertical Port. 
Case A, which represents a "worst case" estimate, can be analyzed in more detail concerning the centerline temperature decline.

With $r=0$, Equation 10 reduces to

$$
\theta(0, t)=\frac{e^{-\alpha t}}{2 \varepsilon_{l} t} \int_{0}^{R_{0}} e^{-R^{2} / 4 \varepsilon_{l} t} R d R
$$

that, when integrated, yields

$$
\theta(0, t)=e^{-\alpha t}\left(1-e^{\left.-R_{0}^{2} / 4 \varepsilon_{l} t\right)}\right.
$$

Figure 12 illustrates values of $\theta(0, t)$ in terms of the parameters at and $\varepsilon_{0} t / R_{0}{ }^{2}$. The rate of centerline temperature decay may be established using Figure 12 for any situation having the initial distribution of Case $A$.

A similar simplification for Case B yields

$$
\left.\theta(0, t)=e^{-\alpha t} \mid \frac{R_{0}^{2}}{R o^{2}+2 \varepsilon_{\ell} f}\right\}
$$

for the maximum centerline temperature.

\section{DISCUSSION}

Fish kills from temperature changes in thermal mixing zones result from a remarkably common phenomenon, attraction to warmed water during winter minimums and repulsion during summer maximums. Since mixing zone regimes represent imposition of discharge temperatures upon ambient, they gradually increase or decrease with changing seasons. Cold shock kills occur, for the most part, during winter when fish inhabiting the warmer mixing zones have become metabolically acclimated to incremental temperatures and cannot survive rapid return to colder, ambient levels.

Physiologically, any upward acclimation to an artificially elevated temperature by a cold-blooded organism is accompanied by decreased resistance to low temperature. This is the underlying cause of sporadic cold shock ki1ls at power stations during winter shutdowns. However, fish inhabiting mixing zones may not acclimate completely to maximum discharge temperatures 


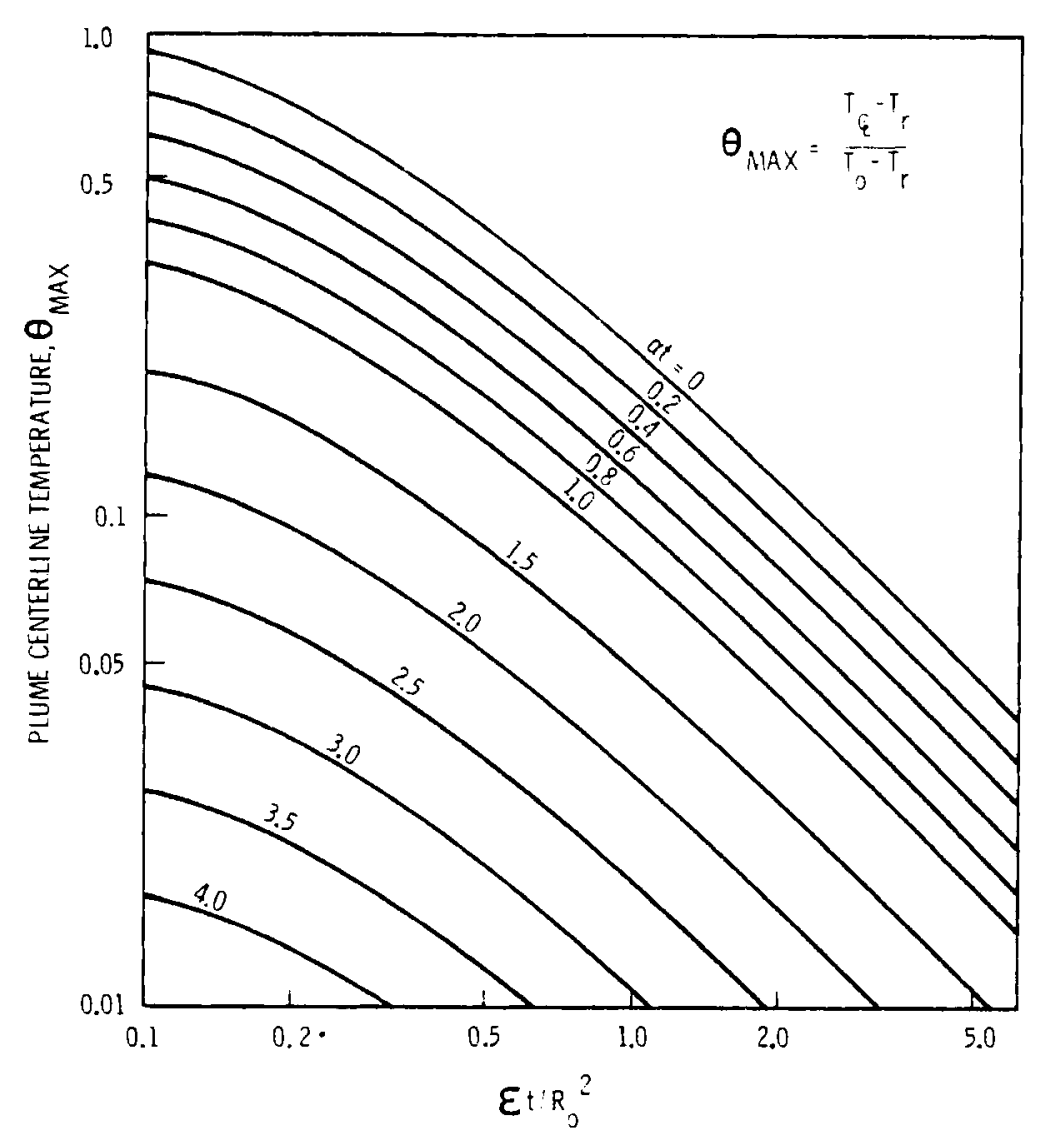

FIGURE 12. Case A. Centerline temperature behavior in terms of $\alpha t$ and $\varepsilon t / R_{0}{ }^{2}$. (Logarithmic coordinates)

(e.g., Kelso, 1976; Neill and Magnuson, 1974; Spigare11i, 1975). Apparently there are often periodic movements to cooler areas, explaining in part why cold shock kills are not more frequent.

Predicting, in advance, the severity of cold shock on aquatic organisms at power plant sites during winter shutdowns is not difficult. The first priority is data on cold resistance of the specific organisms, usualiy fish, attracted to warmed areas and present during the critical winter season. This information is generated from controiled thermal resistance tests. Published data on the resistance of various aquatic organisms to cold shock is rather meager, compared to information on resistance to heat shock (Committee on Water Quality Criteria, 1973; Coutant, 1972b). Considerably more data on 
cold shock effects for various fish species in different geographical regions are needed to expand predictive capacity.

Both examples cited (Lake Wabamum and Susquehanna River) involved abrupt cold shock where the lethality of temperature declines following forced shutdown was predictable. In these cases, temperature declines were not only abrupt but extreme, involving ranges of 16.9 and $24.5^{\circ} \mathrm{C}$, respectively. Temperature declines in mixing zones often encompass a smaller range, and no direct mortalities result. Such events are usually fortuitous rather than intentional.

Data on resistance to abrupt cold shock can be applied to any situation where incremental temperatures return almost instantly to ambient after plant shutdown, for example in rivers, discharge canals, or other situations where water flow is unidirectional. However, the potential for cold shock kill will of ten be lowered if plant operators can gradually reduce discharge temperatures by controlling the shutdown rate. Controlled shutdowns are not possible in emergency closures.

Data on resistance to gradual cold shock can be applied to any situation where hydrologic conditions in mixing zones retard thermal dissipation after plant shutdown. Fish exposed to gradually falling temperatures undergo partial physiological compensation, which effectively increases their cold resistance by extending the lower lethal limit characteristic of each species.

Combining thermal resistance data with plume decay rates is prerequisite for regulatory agencies to establish reliable standards for gradual shutdowns that protect fish from adverse cold shock impact.

We have presented a method for estimating temperature declines in therma 1 plumes that originate from suddenly terminated offshore discharges and undergo spatial and temporal dispersal. The results are two dimensional, and apply wherever there are minimal shear currents and boundary effects.

Our plume decay model is a simplification of a more complex mathematical approach, although based on valid physical laws. Simplification was deemed desirable for efficient application by biological disciplines. Yet reduction 
of the model to fundamentais entails some loss of accuracy arising primarily from kinetic actions that are site specific.

Temperature isopleths predicted by our simplified model have not been validated through field comparisons because of the apparent dearth of twodimensional thermal decay data at existing power plant sites. Emergency shutdowns preclude advance preparations for establishing a proper monitoring program. Furthermore, plume decay rates in relatively static waters after plant shutdowns have been a minor concern, presumably because no adverse ecological impact is usually expected. Sporadic cold shock kills following some winter closures are clearly the exception. Thus the potential for such losses must be examined, particularly for the more valued finfish and shellfish specieș.

A word of caution is required in application of cold shock mortality data from thermal resistance tests to predicting the direct consequences of cold shock in field situations. In heat shock, fish normally pass through a period of hyperactivity before disablement and death. In cold shock, fish normally enter stupor or chill coma before death. Depending on species involved and rate of temperature decline, coma may occur well in advance of the death point. Thus predictions of cold shock impact based only on bioassay mortality will usually underestimate the actual losses (Becker, Genoway and Schneider, 1977). Predictions should be based on the onset of either chill coma or loss of equilibrium rather than cold shock mortality. If not, a suitable "safety factor" must be developed, assessed and applied.

During the time this report was in preparation, the American Nuclear Society's Working Group ANS-18.3 was holding discussions to prepare a draft "standard" document for cold shock in relation to power plant siting, design, and operation. Some considerations of Working Group ANS-18.3 were the bases of a recent publication in the open literature (Coutant, 1977). Although specific Federal regulatory guidelines and/or standards have yet to be approved and issued, this publication provides a comprehensive evaluation of the cold shock situation at power plants. 


\section{ACKNOWLEDGMENTS}

The plume decay model was developed by Don S. Trent to aid with ecological assessment of cold shock impact and cold shock bioassays at PNL. This paper is based on work performed under Contract EY-76-C-06-1830 with the United States Energy Research and Development Administration (now U.S. Department of Energy). 


\section{REFERENCES}

Ackers, P. Modeling of heated-water discharges. Engineering Aspects of Thermal Pollution (Edited by Parker, F. L. and Krenkel, P. A.), pp. 177-212. Vanderbilt Univ. Press, Nashville, Tenn, 1969.

Anon. Thermal pollution fish kill. Bull. Sport Fish. Inst. 223 (April). p. 3, 1971 .

Anon. Thermal fish ki11. Bu11. Sport Fish. Inst. 232 (March). p. 7, 1972. Ash, G. R., Chymko, N. R. and Gallup, D. N. Fish kill due to "cold shock" in Lake Wabamum, Alberta. J. Fish. Res. Board Can. 31, 1822-1824, 1974.

Becker, C. D., Genoway, R. G. and Schneider, M. J. Comparative cold resistance of three Columbia River organisms. Trans. Amer. Fish. Soc. 106, $178-184,1977$.

Brett, J.R. Some principles in the thermal requirements of fishes. Quart. Rev. Biol. 31, 75-87, 1956.

Brett, J. R. Temperature-Animals-Fishes. Marine Ecology, Vol. I, Environmental Factors (Edited by Kinne, 0.), pp. 575-560. Wiley-Interscience, New York, 1970.

Cairns, J., Jr Coping with heated waste water discharges from steam-electric power plants. Bioscience 22, 411-420, 1972.

Carslaw, H. S. and Jaeger, J. C. Conduction of Heat in Solids, 2nd ed. Oxford Univ. Press, London, 1959.

Clark, J. and Brownel1, W. Electric Power Plants in the Coastal Zone: Environmental Issues. Spec. Publ. No. 7, Amer. Littoral Soc., Highlands, N. J. $140 \mathrm{pp} ., 1973$.

Committee on Water Quality Criteria. Water Quality Criteria 1972. Ecological Research Series, EPA-R3-73-033, U.S. Government Printing Office, Washington, DC. 594 pp., 1973.

Coutant, C. C. Biological aspects of thermal pollution I. Entrainment and discharge canal effects. CRC Crit. Rev. Environ. Control 1, 341-381, 1970.

Coutant, C. C. Biological aspects of thermal pollution II. Scientific basis for water temperature standards at power plants. CRC Crit. Rev. Environ. Control 3, 1-24, 1972a.

Coutant, C. C. Time-temperature relationships for thermal resistances of aquatic organisms, principally fish. Publ. ORNL-EIS-72-27, Oak Ridge National Laboratory, Oak Ridge, TN, 1972b. 
Coutant, C. C. Cold shock to aquatic organisms: guidance for power plant siting, design, and operation. Nuclear Safety 18, 329-342, 1977.

Fry, F. E. J. Responses of vertebrate poikilotherms to temperature. Thermobiology (Edited by Rose, A. H.), Chapter 11, pp. 375-409. Academic Press, New York, NY, 1967.

Fry, F. E. J., Hart, J. S. and Walker, K. F. Lethal temperature relations for a sample of young speckled trout, Salvelinus fontinalis. Univ. Toronto Stud., Biol. Ser. 54; Publ. Ontario Fish. Res. Lab. 66, 9-35, 1946.

Hart, J. S. Lethal temperature relations of certain fish of the Toronto region. Trans. Roy. Soc. Can. 51, 57-71, 1947.

Kelso, J. R. M. Movement of yellow perch (Perca flavescens) and white sucker (Catostomus commersoni) in a nearshore Great Lakes habitat subject to a thermal discharge. J. Fish. Res. Board Can. 33, 42-53, 1976.

Nei11, W. H. and Magnuson, J. J. Distributional ecology and behavioral thermoregulation of fishes in relation to a heated effluent from a power plant at Lake Monoma, Wisconsin. Trans. Amer. Fish. Soc. 103, 663-710, 1974.

Pilati, D. A. Transient cooling of a one-dimensional thermal plume and its application for determining cold shock. ORNL-TM-4160, Oak Ridge National Laboratory, Oak Ridge, TN. 16 pp., 1973.

Speakman, J. N. and Krenkel, P. A. Quantification of the effects of rate of temperature change on aquatic biota. Water Res. 6, 1283-1290, 1972.

Spigarelli, S. A. Behavioral responses of Lake Michigan fishes to a nuclear power plant discharge. Environmental Effects of Cooling Systems at Nuclear Power Plants, IAEA-SM-187/18, Int]. Atomic Energy Agency, Vienna, pp. 479$498,1975$.

Stolzenbach, K. D., Adams, E. E. and Harleman, D. R. F. A user's manual for three-dimensional heated surface discharge computations. Environ. Protection Technol. Series, EPA-R2-73-133, U.S. Government Printing office, Washington, DC. 97 pp., 1973. 



\section{DISTRIBUTION}

No. of

Copies

OFFSITE

1 DOE Chicago Patent Group 9800 South Cass Avenue Argonne, IL 60439

A. A. Churm

2 DOE Division of Biomedical and Environmental Research

D. H. Hamilton, Jr.

R. Watters

27 DOE Technical Information Center

\section{ONSITE}

7 DOE Richland Operation Office

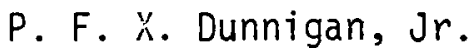

0. J. Elgert

H. E. Ransom

W. Lei

M. W. Tiernan

J. D. White

J. A. Zillich
No. of

Copies

5 United Nuclear Industries

T. E. Dabrowski

J. J. Dorian

R. E. Dunn

M. L. Faught

N. R. Miller

54 Battelle-Northwest

C. D. Becker (20)

C. E. Cushing, Jr.

D. H. Fickeisen

R. F. Foster

C. E. Gibson

R. H. Gray

D. A. Neitzel

T. L. Page

W. H. Rickard

M. J. Schneider (5)

J. A. Strand

W. L. Templeton

D. S. Trent (10)

B. E. Vaughan

D. G. Watson

W. G. Woodfield

Technical Information (5)

Technical Publications (1) 
